\title{
Social Media Use and Physical Activity Participation in College Students: An Exploratory Analysis
}

AMANDA L. FOLK, MS ${ }^{1}$; SARA J. KOVACS, PHD ${ }^{2}$
${ }^{1}$ School of Kinesiology, College of Education and Health Development, University of Minnesota

${ }^{2}$ Department of Kinesiology, College of Public Health, Temple University

Correspondence: folk0039@umn.edu (Amanda L. Folk)

\begin{abstract}
Background: Social media has become a part of a college student's environment, highlighting the importance of investigating the role that social media may play in physical activity (PA) participation and other health behaviors. Purpose: To describe social media use and PA participation in a sample of college students and explore relationships between social media and $P A$, including health and fitness social media. Methods: College students (age 18-29 years) enrolled at a four-year university during the 2018-19 academic year completed an online questionnaire regarding self-reported social media use and PA participation. Independent sample t-tests were used to compare $P A$ outcomes between those that follow bealth and fitness accounts and those who do not. A multiple linear regression model was used to examine associations between social media use and $P A$. Results: Two hundred and ninety-two students completed the questionnaire (63.72\% female, $63.61 \%$ white). There was no difference in $P A$ participation between those that do and do not follow health and fitness social media in moderate $(p=0.40)$ or vigorous intensity $P A(p=0.06)$ when controlling for confounding variables. Spending 1-2 hours/day $(p=0.02)$ or 3-4 hours/day ( $p=0.01)$ on social media compared to $<1$ hour/day and accessing social media in the evening $(p=0.04)$ are associated with lower moderate P A. Conclusions: Following health and fitness social media may not have the intended impact on college student $P A$. Further research needs to be done to assess the most effective and impactful strategies for content delivery via social media to increase $P A$ behavior.
\end{abstract}

Keywords: college student physical activity, social media, exercise, bealth promotion

\section{Introduction}

Physical activity (PA) is associated with numerous positive health outcomes which are realized regardless of age, sex, and body weight. ${ }^{1}$ Health benefits of regular PA include reduction in risk for all-cause mortality, cardiovascular morbidity and mortality, type 2 diabetes, and certain cancers. ${ }^{1,2}$ Some benefits from PA are realized immediately, including acute reductions in anxiety symptoms and blood pressure. ${ }^{1}$ The American College Health Association reported that $31.4 \%$ of college students surveyed in Fall 2020 reported anxiety as affecting their individual academic performance, which was second only to stress. ${ }^{3}$ Since PA has the potential to reduce anxiety and improve health, as well as reduce the risk for many common chronic conditions, encouraging college students to be physically active is essential.

The minimum aerobic PA recommendation, per the 2018 Physical Activity 
Guidelines, is 150 minutes of moderate intensity $\mathrm{PA}, 75$ minutes of vigorous intensity $\mathrm{PA}$, or a combination of the two per week to accrue these health benefits. ${ }^{1}$ Despite the numerous benefits college students can gain from being physically active, studies indicate that PA participation in college students is often below recommended guidelines and that PA participation further tends to decrease each semester of college. ${ }^{4-6}$ Recent data suggest over one third of college students are physically inactive, as per the aerobic guidelines. 3,7 There may be an association between meeting PA guidelines and better mental health outcomes, ${ }^{7}$ and thus PA promotion has been identified as a priority for some institutions. ${ }^{8}$ College is an opportunity for young adults to make independent decisions about their behaviors. It is a crucial time for promoting health and sustainable PA behaviors that may continue into adulthood. ${ }^{9}$ Identifying determinants of PA, as well as effective and feasible strategies for PA promotion among college students, may help these young adults meet activity guidelines and benefit from the associated health effects.

While college students in general seem to have low PA participation, it is clear that they are spending their time regularly engaging with social media. Social media serves as a platform for communication activities and examples include online social networks such as Twitter, Facebook, YouTube, and Instagram. ${ }^{10}$ It is estimated that $90 \%$ of American adults ages 1829 use social media, ${ }^{11}$ up from $12 \%$ in $2005 .{ }^{12}$ Social media has become a part of a college student's environment, indicated by its rapid growth, highlighting the importance of investigating the role that social media may play in PA participation and other health behaviors.

There is currently a gap in the literature regarding the relationship between college social media use and PA participation. One study reported no relationship between social media use and PA engagement in a sample of 512 college students. However, it should be noted that the study only recruited students that were enrolled in for-credit PA and nutrition classes so may not be representative of the general college student population. ${ }^{13}$ Screen time, defined as time spent using computers, watching television or DVDs, and/or playing video games, has been shown to be related to American college students being sufficiently active or not. ${ }^{14,15}$ Screen time may include social media use, but does not capture the specific effect of social media and thus it is essential to separate the two to gain a clearer picture as to how social media affects PA. For example, a focus group of 17 male and 29 female college students in Belgium highlighted internet communication and technology as a behavior leading to sedentary behavior whereas media and advertising as a factor influencing PA behavior. ${ }^{16}$ Since both internet communication and media and advertising are central on social media, further exploration is needed into these relationships. Relationships are seen between social media and health behaviors such as alcohol consumption, indicating that what individuals see on social media may influence other health behaviors, like PA. ${ }^{10,17}$ However, the relationship between following health and fitness social media accounts and PA behavior is unexplored.

One objective of the present study was to describe social media use characteristics and PA behaviors in a representative sample of college students and further examine the relationships between those variables. The researchers also aimed to see if average minutes per week of PA differed between those who reported following health and fitness social media accounts or not. If health and fitness social media were effective in its current form as promoting PA behavior, there will be a difference in average PA levels between participants who follow health and fitness social media accounts and those that do not. Finally, the researchers aimed to identify if social media use variables (i.e., hours spent on social media, social media use patterns) were associated with moderate or vigorous intensity PA while accounting for demographic variables. The researchers hypothesized that time spent on social media and time of day spent on social media would be associated with PA behavior. 


\section{Materials and Methods}

This study was conducted with students enrolled at a four-year university in the United States during the Fall and Spring semesters of the 2018-2019 academic year. College students

\section{Survey Measures}

Social Media Use: The questionnaire included questions regarding a college student's social media use, both in terms of content and timing. Participants were asked if they used social media daily and, if yes, which social media platforms they interacted with daily. Participants were also asked how many hours per day (on average) do they use social media, what time of day they use social media the most, and when do they access social media (e.g., when they wake up, during mealtimes). Finally, participants were queried on if they specifically follow health and fitness social media accounts, which was intentionally inclusive of whatever the participants deemed as "health and fitness."

\section{Participants}

Students were recruited through an email sent to all students enrolled in classes in the College of Public Health at a four-year university, which includes Kinesiology, Communication Sciences and Disorders, Epidemiology and Biostatistics, Health and Rehabilitation Sciences, Health Services Administration and Policy, Nursing, School of Social Work, and Social and Behavioral Sciences Departments. While this was a convenience sample, students outside of these departments were able to take this survey if shared with them through peers. Students were eligible to participate if they were between 18 and 29 years

\section{Statistical Analyses}

Statistical analyses were conducted using SAS version 9.4. In order to describe the sample, means and standard deviations or frequencies were calculated for each of the demographic, social media use, and PA completed a one-time questionnaire regarding social media use and PA participation. The questionnaire was supported through Qualtrics software, an online survey platform.

Self-Report Physical Activity. Physical activity was measured through self-report using the International Physical Activity Questionnaire - Short Form, which has been validated in a college student population. ${ }^{18}$ This questionnaire asks participants to think about the vigorous- and moderate- intensity PA they have done in the past seven days and identify how many of those days they did that type of activity, as well as how much time they usually spent doing that type of PA on one of those days. The number of days is multiplied by this duration to calculate average minutes per week of a given intensity of PA. ${ }^{19}$

old and a student currently registered for classes during the semesters of data collection. Informed consent was obtained from participants on the first page of the online questionnaire.

At the end of data collection, 394 survey responses were recorded. Responses from students who did not meet the age inclusion criteria or who were not currently registered for classes were excluded. Additionally, incomplete responses were excluded. The final number of participants included in this study was 292.

variables. Independent sample t-tests were used to compare mean PA outcomes between those that follow health and fitness accounts and those who do not to see if there was a difference in average PA between groups. Finally, a 
multiple linear regression model was used to examine potential associations between social media use and PA. The linear regression model included hours of social media use per day, the time social media was most accessed, and whether or not health and fitness accounts are part of the social media consumption. Additionally, sex and residence were entered into the model to be controlled for, as both have been shown to affect PA in college-aged individuals ${ }^{6}$. Statistical significance was set at $\mathrm{p}$ $\leq$ 0.05. Temple University's Institutional Review Board deemed the study met exemption status due to minimal risk involvement and anonymous survey methodology.

\section{Results}

Demographics, social media use, and self-reported PA behavior of the entire sample can be found in Table 1. The majority of the sample was compromised of females (69.7\%) and White individuals (63.6\%). A majority of the sample reported using social media daily (96.6\%), with most of the sample reporting either 1-2 hours or 3-4 hours of social media use per day $(41.4 \%$ and $43.1 \%$, respectively). Instagram was the most popular social media platform used by the sample, followed by Snapchat. Over half of the sample (55.9\%) reported the most popular hours of use between $8 \mathrm{pm}$ and 12am. Those that reported following health and fitness accounts $(n=228 ; 78.6 \%)$ reported an average of $189.4 \pm 178.0 \mathrm{~min} /$ week of moderate PA and $268.9 \pm 197.7 \mathrm{~min} /$ week of vigorous PA. In contrast, those that reported not following health and fitness accounts reported an average of $164.2 \pm 158.6 \mathrm{~min} /$ week and $270.9 \pm 249.6 \mathrm{~min} /$ week, respectively. There were no statistically significant differences for either moderate $(p=0.40)$ or vigorous $(p=0.06)$ intensities of PA between those who report following health and fitness accounts and those who do not.

\begin{tabular}{|c|c|}
\hline $\begin{array}{l}\text { Table } 1 . \\
\text { Survey Results: Demographics, Social } \\
\text { Physical Activity }\end{array}$ & Ledia Use, \& \\
\hline Demographics & $\begin{array}{c}\text { Mean } \pm \text { SD or } \\
n(\%)\end{array}$ \\
\hline Sex* & \\
\hline Female & 205 (69.73) \\
\hline Male & $89(30.27)$ \\
\hline Race/Ethnicity & \\
\hline White & 187 (63.61) \\
\hline African American or Black & $39(13.27)$ \\
\hline Hispanic or Latinx & $27(9.18)$ \\
\hline Native American & $1(0.34)$ \\
\hline Asian & $39(13.27)$ \\
\hline Two or More Races & $11(3.74)$ \\
\hline Other & $17(5.78)$ \\
\hline Residence & \\
\hline University-Owned Housing & $69(23.47)$ \\
\hline Home of parents/relative & $64(21.77)$ \\
\hline Own home/apartment & $154(52.38)$ \\
\hline With other family members & $1(0.34)$ \\
\hline Other & $6(2.04)$ \\
\hline Social Media Use & \\
\hline Use social media daily & $284(96.60)$ \\
\hline Use Facebook & $154(52.38)$ \\
\hline Use Twitter & $134(45.58)$ \\
\hline Use Instagram & $259(88.10)$ \\
\hline Use YouTube & $150(51.19)$ \\
\hline Use Snapchat & $240(81.63)$ \\
\hline Use other & $22(7.48)$ \\
\hline $\begin{array}{l}\text { What time of day do you use soc } \\
\text { most? }\end{array}$ & 1 media the \\
\hline Morning (6am-10am) & $13(4.48)$ \\
\hline Mid-day (11am-2pm) & $15(5.17)$ \\
\hline Afternoon (3pm-7pm) & $100(34.48)$ \\
\hline Evening (8pm-12am) & $162(55.86)$ \\
\hline How many hours per day do you & sse social media? \\
\hline$<1$ bour & $22(7.59)$ \\
\hline 1-2 bours & $120(41.38)$ \\
\hline 3-4 hours & $125(43.10)$ \\
\hline $5+$ bours & $23(7.93)$ \\
\hline $\begin{array}{l}\text { Follow health/fitness accounts } \\
\text { on social media }\end{array}$ & $228(78.62)$ \\
\hline Physical Activity Behavior & \\
\hline Moderate (min/week) & $184.45 \pm 174.23$ \\
\hline Vigorous (min/week) & $269.20 \pm 206.32$ \\
\hline
\end{tabular}

\section{CommonHealth}


Results from multiple linear regression models can be found in Table 2 for moderate intensity PA and Table 3 for vigorous intensity PA. Those that follow health and fitness accounts participate in moderate intensity PA. average 42.90 more min/week than those who do not when controlling for sex, residence, how often an individual uses social media, and what time of day social media is used. This effect is not statistically significant $(\mathrm{p}=0.21)$ but may be interesting to note. Also of note is the effect of amount of social media use on moderate intensity PA.

When compared to those that use social media less than one hour per day, those who used social media between 1-2 hours report on average 104.96 fewer minutes of moderate PA per week $(p=0.02)$ and those who used social media between 3-4 hours per day report on average 116.65 fewer minutes of moderate PA per week $(p=0.01)$. Time of day that social media is accessed most may also be associated with moderate PA. Those who accessed social media most in the evening reported participating in, on average, 126.81 fewer minutes of moderate intensity PA per week compared to those who access social media most in the morning $(\mathrm{p}=0.04)$.

While not statistically significant $(p=0.06)$, those who accessed social media most in the afternoon reported, on average 116.48 minutes per week fewer than those who most engaged with social media in the morning. The results regarding vigorous $\mathrm{PA}$, however, are different. Those that followed health and fitness accounts participated in vigorous intensity $\mathrm{PA}$ only an average of 0.02 more min/week than those who do not when controlling for sex, residence, how often an individual uses social media, and what time of day social media is used.

\begin{tabular}{|c|c|c|c|c|}
\hline Parameter & $\beta$ Estimate & SE & t-value & p-value \\
\hline BMI & -3.31 & 2.98 & -1.11 & 0.27 \\
\hline \multicolumn{5}{|l|}{ Sex } \\
\hline Females & -46.74 & 30.93 & -1.73 & 0.08 \\
\hline Males $^{1}$ & - & - & - & - \\
\hline \multicolumn{5}{|l|}{ Residence } \\
\hline Home of parents/relatives & -49.28 & 37.86 & -1.30 & 0.19 \\
\hline Own home/apartment & -21.57 & 31.22 & -0.69 & 0.49 \\
\hline With other family members & -155.77 & 182.80 & -0.85 & 0.40 \\
\hline Other & -31.80 & 91.73 & -0.35 & 0.73 \\
\hline University-Owned Housing ${ }^{1}$ & - & - & - & - \\
\hline \multicolumn{5}{|l|}{ Social Media Use: hours/day } \\
\hline 1-2 Hours & -108.02 & 44.08 & -2.45 & $0.02 *$ \\
\hline 3-4 Hours & -120.91 & 45.61 & -2.65 & $0.01 * *$ \\
\hline $5+$ Hours & -7.64 & 65.00 & -0.12 & 0.91 \\
\hline$<1$ Hour $^{1}$ & - & - & - & - \\
\hline \multicolumn{5}{|l|}{ Social Media Use: time of day } \\
\hline Mid-Day & -86.64 & 86.34 & -1.00 & 0.32 \\
\hline Afternoon & -108.53 & 62.53 & -1.74 & 0.08 \\
\hline Evening & -122.56 & 60.52 & -2.03 & $0.04^{*}$ \\
\hline Morning ${ }^{1}$ & - & - & - & - \\
\hline \multicolumn{5}{|l|}{ Follows Health \& Fitness Account } \\
\hline Yes & 42.90 & 30.93 & 1.39 & 0.17 \\
\hline $\mathrm{No}^{1}$ & - & - & - & - \\
\hline
\end{tabular}




\begin{tabular}{|c|c|c|c|c|}
\hline Parameter & $\beta$ Estimate & SE & t-value & p-value \\
\hline BMI & -0.30 & 3.47 & -0.09 & 0.93 \\
\hline \multicolumn{5}{|l|}{ Sex } \\
\hline Females & -91.34 & 31.28 & -2.92 & $0.004 * *$ \\
\hline Males ${ }^{1}$ & - & - & - & - \\
\hline \multicolumn{5}{|l|}{ Residence } \\
\hline Home of parents/relatives & -76.58 & 45.54 & -1.68 & 0.09 \\
\hline Own home/apartment & -64.58 & 34.20 & -1.89 & 0.06 \\
\hline With other family members & -277.76 & 219.52 & -1.27 & 0.21 \\
\hline Other & -102.78 & 109.08 & -0.94 & 0.35 \\
\hline University-Owned Housing 1 & - & - & - & - \\
\hline \multicolumn{5}{|l|}{ Social Media Use: hours/day } \\
\hline 1-2 Hours & 2.98 & 51.09 & 0.06 & 0.95 \\
\hline 3-4 Hours & -29.56 & 52.65 & -0.56 & 0.58 \\
\hline $5+$ Hours & 50.33 & 73.24 & 0.69 & 0.49 \\
\hline$<1$ Hour $^{1}$ & - & - & - & - \\
\hline \multicolumn{5}{|l|}{ Social Media Use: time of day } \\
\hline Mid-Day & -39.95 & 97.47 & -0.41 & 0.68 \\
\hline Afternoon & 48.90 & 75.22 & 0.65 & 0.52 \\
\hline Evening & 32.51 & 72.93 & 0.45 & 0.66 \\
\hline Morning $^{1}$ & - & - & - & - \\
\hline \multicolumn{5}{|l|}{ Follows Health \& Fitness Account } \\
\hline Yes & 0.17 & 38.90 & 0.00 & 1.00 \\
\hline $\mathrm{No}^{1}$ & - & - & - & - \\
\hline
\end{tabular}

This effect is not statistically significant $(p=1.00)$. Interestingly, there seems to be no statistically significant effect of number of hours

\section{Discussion}

This study aimed to explore social media use characteristics and PA in a representative sample of college students. Most participants in the sample use social media daily (96.6\%), which is not unlike national samples. ${ }^{11}$ Further, almost $79 \%$ of the sample follows some sort of health and fitness channel on social media and it is clear in the literature that young people are getting health information from social media. ${ }^{20}$ Data from the present study do not indicate students who are receiving health and fitness content are participating more in favorable health behavior. Indeed, there is no statistically significant effect of following these per day social media is used on vigorous intensity PA, nor an association with time of day that social media is most used social media channels on either moderate or vigorous $\mathrm{PA}$.

Despite this lack of significant effect, literature suggests social media seems to be a potential intervention strategy for changing health behaviors, including increasing PA. ${ }^{21-23}$ However, it should be noted that almost all of the currently existing intervention studies used Facebook as the social media platform in the interventions. ${ }^{24}$ Out of three interventions specifically in college students with the goal of increasing PA, two used Facebook and one used a platform unique to the study. ${ }^{25-27}$ Facebook may be useful as a tool to increase social support 
and encourage PA behaviors. ${ }^{26}$ If the goal is to reach all college students, however, data from the present study indicate that Facebook may not be reaching the general college student, as only $52.4 \%$ of the sample reported using Facebook each day. Facebook had the lowest engagement of all social media platforms included in this questionnaire; this tends to differ from studies looking at social media use across adulthood. ${ }^{28}$

There is some evidence that people who are not regularly physically active can be influenced to be active through content such as workout posts. ${ }^{28}$ However, the present sample suggests health and fitness channels as they exist now do not seem to be associated with more PA in the sample of college aged participants. Perhaps the content is not effectively promoting PA behavior or the students are not actually seeing or engaging with that content, due to social media algorithms that are unknown to the public. ${ }^{29}$ Further qualitative studies focusing on accurately assessing what health and fitnessrelated content college aged students are viewing and interacting with on their social media feeds is warranted. This type of analysis will provide much needed insight to researchers who intend to use social media as an intervention tool for behavior change, specifically an increase in PA behavior.

This study did have strengths, one of which is reflected in the sample itself. This is the first survey to the research team's knowledge that surveyed a sample that was not comprised of those students only enrolled in PA participation classes. ${ }^{13}$ Since enrollment in these types of classes may already influence a participant's PA behavior, the present sample may be more generalizable to a student body. Additionally, this is the first study to the research team's knowledge that contained survey questions specifically related to health and fitness accounts on social media. Descriptive data of this kind is essential when examining social media as a potential intervention strategy for PA. An additional strength is related to the demographics of the students surveyed. The research team was able to recruit a sample that is representative of the student body of the university. Temple
University is an urban campus, so the results may not be generalizable to all college campuses.

Many of the weaknesses of this study are a result of the survey study design. The data presented are cross-sectional in nature, therefore, no causal relationships were able to be explored. Additionally, the sample size is small relative to a typical college campus and was predominantly female. While a smaller sample size may be acceptable for the first steps of establishing these relationships, further surveys should be conducted in a larger sample. Finally, there are limits to the generalizability of this study. While participants were not limited to belonging to the University's College of Public Health, classes in the College were used as a starting point for recruitment. This convenience sample may lead to a higher proportion of participants who are interested in health and fitness.

The survey questions also may have led to some challenges that provide opportunities for further research studies to capitalize on. The PA survey questions were from the International Physical Activity Questionnaire Short Form. These have been validated in a college-aged sample, ${ }^{18}$ but did not seem to result in an overall average realistic response in the sample. For example, the average amount of vigorous PA in the sample was $269.2 \pm 206.3$ minutes per week. There is a known tendency for individuals to over report $\mathrm{PA},{ }^{30}$ particularly college students using IPAQ, ${ }^{31}$ and some of the relationships analyzed as part of this study may be affected as a result. The variability in PA data indicates a need for objectively collected PA data in a college aged sample as a next step. While there are no validated survey questions regarding social media for this population to the researcher's knowledge, social media can be challenging to research because of the constantly changing nature of platform popularity. For example, this survey did not include TikTok and only one participant reported using it regularly under the response of "Other." While the options presented were reasonable for the time of the initial survey, TikTok has become increasingly popular and would need to be included in further surveys. 
Additional research may be of interest to universities in different locations. As previously mentioned, this survey was conducted on an urban campus. Perhaps this is not generalizable to, for example, a rural college town. Next steps could involve looking at different university locations with similar surveys to see if results differ between institutions. While this survey is the first of its kind to question participants on health and fitness accounts specifically, more research needs to be done regarding what specifically these students are seeing. This will be crucial for social media intervention design and implementation to ultimately increase PA in college aged students. Finally, many college students are experiencing a strain on their mental health in terms of being overwhelmed, stressed, exhausted, and/or lonely. ${ }^{3} \mathrm{PA}$ is often cited for its brain health benefits (reduced anxiety and depression risk; improved quality of life), so increasing PA in college students is of the utmost importance ${ }^{1}$ It remains unclear if social media is responsible for mental health problems among young adults, though one study suggests how social media is used may be more insightful than general use patterns. ${ }^{32}$
Thus, future studies intervening upon PA using social media, or further exploring relationships between the two, may want to include mental health as a secondary outcome variable to ensure the intervention is protecting and not further affecting their mental health.

In conclusion, this study provides descriptive statistics for an urban university regarding social media use and PA behavior. There were no statistically significant differences in self-reported PA behavior between those that follow health and fitness social media accounts and those that do not. However, the difference in moderate intensity PA may be practically significant; those that follow health and fitness accounts on average reported engaging in $42.9 \mathrm{~min} /$ week more compared to those that do not follow health and fitness accounts. Time spent on social media per day seems to be associated with moderate PA, as well as time of day social media is most accessed. Results from this study could be used to inform further social-media related research in college students, as well as inform professionals who use social media as a tool to encourage PA behaviors in college students.

\section{Conflicts of Interest}

The authors have no conflicts of interest.

\section{ORCID IDs}

Amanda L. Folk - 0000-0001-8424-9265

Sara J. Kovacs - 0000-0002-5000-7900

\section{Statement of Contributions}

Conceptualization, A.L.F., S.J.K.; methodology, A.L.F., S.J.K.; formal analysis, A.L.F.; writing-original draft preparation, A.L.F.; writing-review and editing, A.L.F., S.J.K. All authors have read and agreed to the published version of the manuscript.

\section{References}

1. Piercy KL, Troiano RP, Ballard RM, et al. The Physical Activity Guidelines for Americans. JAMA. 2018;320(19):2020. doi:10.1001/jama.2018.14854

2. Warburton DER. Health benefits of physical activity: the evidence. Canadian Medical Association Journal. 2006;174(6):801-809. doi:10.1503/cmaj.051351

3. American College Health Association. American College Health Association-National College Health Assessment III: Reference Group Executive Summary Fall 2020. American College Health Association; 2020. Accessed May 20, 2020. 
https://www.acha.org/documents/ncha/NCHA-

II_SPRING_2019_US_REFERENCE_GROUP_EXECUTIVE_SUMMARY.pdf

4. Buckworth J, Nigg C. Physical Activity, Exercise, and Sedentary Behavior in College Students. Journal of American College Health. 2004;53(1):28-34. doi:10.3200/JACH.53.1.28-34

5. Keating XD, Guan J, Piñero JC, Bridges DM. A Meta-Analysis of College Students' Physical Activity Behaviors. Journal of American College Health. 2005;54(2):116-126. doi:10.3200/JACH.54.2.116-126

6. Small M, Bailey-Davis L, Morgan N, Maggs J. Changes in Eating and Physical Activity Behaviors Across Seven Semesters of College: Living On or Off Campus Matters. Health Educ Behav. 2013;40(4):435-441. doi:10.1177/1090198112467801

7. Murphy MH, Carlin A, Woods C, et al. Active Students Are Healthier and Happier Than Their Inactive Peers: The Results of a Large Representative Cross-Sectional Study of University Students in Ireland. Journal of Physical Activity and Health. 2018;15(10):737-746. doi:10.1123/jpah.2017-0432

8. New York University. Physical Activity. Live Well NYU. Accessed November 18, 2021. http://www.nyu.edu/content/nyu/en/life/safety-health-wellness/live-well-nyu/priorityareas/physical-activity

9. Deforche B, Van Dyck D, Deliens T, De Bourdeaudhuij I. Changes in weight, physical activity, sedentary behaviour and dietary intake during the transition to higher education: a prospective study. Int J Behav Nutr Phys Act. 2015;12(1):16. doi:10.1186/s12966-015-0173-9

10. Williams G, Hamm MP, Shulhan J, Vandermeer B, Hartling L. Social media interventions for diet and exercise behaviours: a systematic review and meta-analysis of randomised controlled trials. BMJ Open. 2014;4(2):e003926. doi:10.1136/bmjopen-2013-003926

11. U.S. social reach by age 2019. Statista. Accessed November 17, 2021. https://www.statista.com/statistics/471370/us-adults-who-use-social-networks-age/

12. Perrin A. Social Media Usage: 2005-2015. Pew Research Center; 2015:12. http://www.pewinternet.org/2015/10/08/2015/Social-Networking-Usage-2005-2015/

13. Calestine J, Bopp M, Bopp CM, Papalia Z. College Student Work Habits are Related to Physical Activity and Fitness. International Journal of Exercise Science. 2017;10(7):1009-1017.

14. Fountaine CJ, Liguori GA, Mozumdar A, Schuna JMJr. Physical Activity and Screen Time Sedentary Behaviors in College Students. International Journal of Exercise Science. 2011;4(2):11.

15. Marshall SJ, Gorely T, Biddle SJH. A descriptive epidemiology of screen-based media use in youth: A review and critique. Journal of Adolescence. 2006;29(3):333-349. doi:10.1016/j.adolescence.2005.08.016

16. Deliens T, Deforche B, De Bourdeaudhuij I, Clarys P. Determinants of physical activity and sedentary behaviour in university students: a qualitative study using focus group discussions. BMC Public Health. 2015;15(1):201. doi:10.1186/s12889-015-1553-4

17. Hoffman EW, Pinkleton BE, Weintraub Austin E, Reyes-Velázquez W. Exploring College Students' Use of General and Alcohol-Related Social Media and Their Associations With Alcohol-Related Behaviors. Journal of American College Health. 2014;62(5):328-335. doi:10.1080/07448481.2014.902837

18. Dinger MK, Behrens TK, Han JL. Validity and Reliability of the International Physical Activity Questionnaire in College Students. American Journal of Health Education. 2006;37(6):337-343. doi:10.1080/19325037.2006.10598924

19. Craig CL, Marshall AL, Sj??Str??M M, et al. International Physical Activity Questionnaire: 12 Country Reliability and Validity: Medicine \& Science in Sports \& Exercise. 2003;35(8):1381-1395. doi:10.1249/01.MSS.0000078924.61453.FB

20. Goodyear VA, Armour KM, Wood H. Young people and their engagement with health-related social media: new perspectives. Sport, Education and Society. 2019;24(7):673-688. doi:10.1080/13573322.2017.1423464 
21. Yang Q. Are Social Networking Sites Making Health Behavior Change Interventions More Effective? A Meta-Analytic Review. Journal of Health Communication. 2017;22(3):223-233. doi:10.1080/10810730.2016.1271065

22. Welch V, Petkovic J, Simeon R, et al. Interactive social media interventions for health behaviour change, health outcomes, and health equity in the adult population. Cochrane Database of Systematic Reviews. 2018;(2). doi:10.1002/14651858.CD012932

23. Müller AM, Maher CA, Vandelanotte C, et al. Physical Activity, Sedentary Behavior, and DietRelated eHealth and mHealth Research: Bibliometric Analysis. J Med Internet Res. 2018;20(4). doi:10.2196/jmir.8954

24. Johns DJ, Langley TE, Lewis S. Use of social media for the delivery of health promotion on smoking, nutrition, and physical activity: a systematic review. The Lancet. 2017;390:S49. doi:10.1016/S0140-6736(17)32984-7

25. Pope Z, Barr-Anderson D, Lewis B, Pereira M, Gao Z. Use of Wearable Technology and Social Media to Improve Physical Activity and Dietary Behaviors among College Students: A 12-Week Randomized Pilot Study. IJERPH. 2019;16(19):3579. doi:10.3390/ijerph16193579

26. Rote AE, Klos LA, Brondino MJ, Harley AE, Swartz AM. The Efficacy of a Walking Intervention Using Social Media to Increase Physical Activity: A Randomized Trial. Journal of Physical Activity and Health. 2015;12(s1):S18-S25. doi:10.1123/jpah.2014-0279

27. Zhang J, Brackbill D, Yang S, Centola D. Efficacy and causal mechanism of an online social media intervention to increase physical activity: Results of a randomized controlled trial. Preventive Medicine Reports. 2015;2:651-657. doi:10.1016/j.pmedr.2015.08.005

28. Goodyear VA, Boardley I, Chiou SY, et al. Guidelines for using social media to inform behaviours related to physical activity, diet and quality of life. Published online 2021. doi:10.25500/EPAPERS.BHAM.00003431

29. Vandelanotte C, Kirwan M, Rebar A, et al. Examining the use of evidence-based and social media supported tools in freely accessible physical activity intervention websites. Int J Behav Nutr Phys Act. 2014;11(1):105. doi:10.1186/s12966-014-0105-0

30. Montoye HJ, Kemper HC, Washburn RA, Saris WH. Measuring Physical Activity and Energy Expenditure. Human Kinetics; 1996.

31. Downs A, Van Hoomissen J, Lafrenz A, Julka DL. Accelerometer-Measured Versus Selfreported Physical Activity in College Students: Implications for Research and Practice. Journal of American College Health. 2014;62(3):204-212. doi:10.1080/07448481.2013.877018

32. Berryman C, Ferguson CJ, Negy C. Social Media Use and Mental Health among Young Adults. Psychiatr Q. 2018;89(2):307-314. doi:10.1007/s11126-017-9535-6 